\title{
Impact of Battery Charging of Electric Vehicles on Power Quality in Smart Homes and Low-Voltage Distribution Networks
}

\author{
D. S. Batorowicz ${ }^{1}$, H. Zimmer ${ }^{1}$, P. Franz ${ }^{1}$ and J. Hanson ${ }^{1}$ \\ ${ }^{1}$ Department of Electrical Power Supply with Integration of Renewable Energies \\ Technische Universität Darmstadt \\ Landgraf-Georg-Str. 4, 64283 Darmstadt (Germany) \\ Phone number: 0049615116 24672, e-mail: damian.batorowicz@e5.tu-darmstadt.de
}

\begin{abstract}
The German federal government is aiming towards one million electric vehicles by 2020 [1]. The battery charging of electric vehicles in low-voltage networks with high penetration of power electronic devices is the scope of this investigation. Due to an increase of the number of electric vehicles, the changes of power quality and violation of predefined limits are evaluated. This analysis gives information about expected power quality and challenges for the distribution network operators and the manufacturers to conform present standards.
\end{abstract}

\section{Key words}

Power quality, electric vehicle, smart home, harmonic voltages, voltage unbalance

\section{Introduction}

The smart building technology of private houses is a crucial part of the future development of home electric installations. Increasing numbers of electric vehicles as well as parallel improvement of network of charging stations are significantly influencing the power quality in household areas and low-voltage (LV) networks $\left(U_{\mathrm{n}} \leq 1 \mathrm{kV}\right)[2,3]$. Due to installed non-linear power electronic devices in private as well as in industry networks, a degradation of the local power quality is observed in practice [4,5]. Therefore, those grids with high penetration of converters should be monitored especially and power quality violations should be investigated.

In low-voltage networks, the power quality influences connected loads and their energy efficiency during operation. One responsible unit for the technical adherence to power quality standards (such as EN 50160 [6]) is the local distribution network operator [2]. Due to network operator and manufacturer limits (such as IEC 61000-3-2 [7,8]), the influences of electric vehicles and corresponding charging stations should be kept to a minimum.

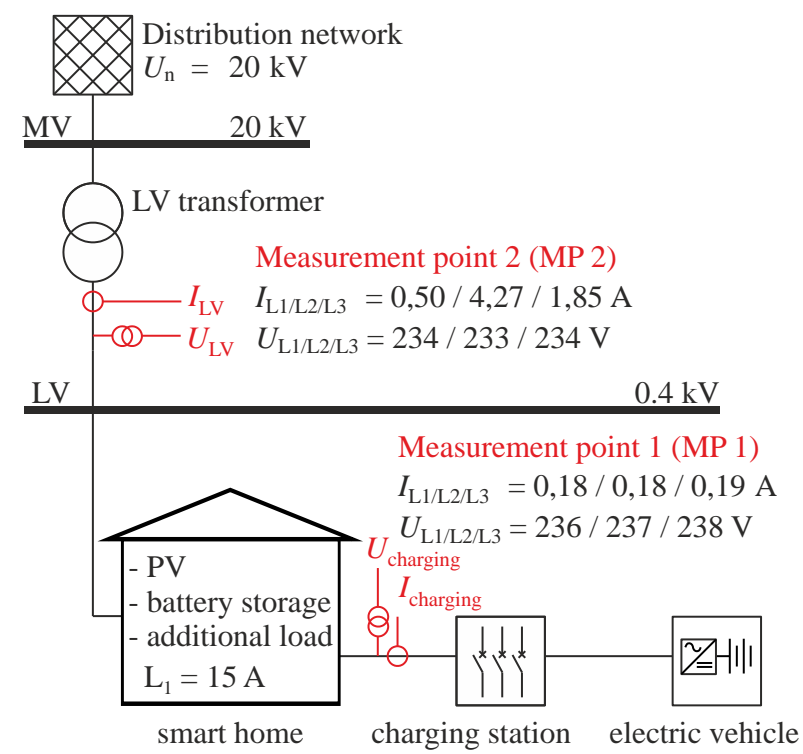

Fig. 1. Overview of power quality measurement.

Figure 1 shows the overview of the investigated network with the smart home connected to the low-voltage distribution transformer and a charging station installed close to the house. The investigated charging station allows simultaneous charging of two electric vehicles with the maximum output power of $11 \mathrm{~kW}$ on each plugin terminal. For the investigation of the power quality two measurement points (MP 1 and MP 2) are chosen, one at the end of the feeder cable close to the charging station and one at the LV side of the transformer. The visible phase voltages and currents (see Fig. 1) are measured in a no-charging scenario before the battery charging starts.

\section{Analysis of power quality}

Generally speaking, power quality describes defined parameters of voltage wave form characteristics and their permitted margins for network operation. For the assessment of power quality during battery charging, two measurable sets of the following parameters are chosen. 
Harmonic voltages $u_{\mathrm{h}}$ (sinusoidal voltages with integer multiples of the fundamental frequency) describe the wave form of phase to ground voltage. The harmonic voltages characterise the impact of electrical equipment e.g. a power electronic device on network. As a measure of all harmonic voltages, the total harmonic distortion (THD) is defined as one parameter according to eqn. (1).

$$
T H D=\sqrt{\sum_{h=2}^{n} u_{h}^{2}}
$$

The voltage unbalance $u_{\mathrm{u}}$ as the second parameter describes the coherence between the negative system $\underline{U}_{2}$ to the positive system $\underline{U}_{1}$ of the phase voltage and is defined as the mean ratio within a 10 min time period; see eqn. (2).

$$
u_{\mathrm{u}}=\left|\frac{\underline{U}_{2}}{\underline{U}_{1}}\right|
$$

The maximum permitted voltage unbalance of $2 \%$ during $95 \%$ of the measured time and limitations for each harmonic up to $1250 \mathrm{~Hz}$ (25th harmonic in $50-\mathrm{Hz}$ networks) are defined in the standard EN 50160 [2]. In accordance to this standard, the harmonics up to $n=40$ have to be considered in the calculation of the THD factor, which should be lower than $8 \%$.

\section{A. Laboratory measurements}

The measurements of battery charging of electric vehicles in the laboratory (LAB) at the Technische Universität Darmstadt are the motivation of investigating the power quality in a real household connected directly to a public network. Three different electric vehicles are considered. The battery of Vehicle A is a three-phase charging system with a maximum charging current in each phase of $32 \mathrm{~A}$ (charging power amounts to $22 \mathrm{~kW}$ ). Due to the maximum output power of the charging station of up to $11 \mathrm{~kW}$, the charging current is limited to $16 \mathrm{~A}$. The Vehicles B and C are only capable of being single-phase charging and their maximum charging current amounts to 13,3 A and 14,3 A, respectively. Vehicles A and B are purely electric driven in contrast to the hybrid vehicle $\mathrm{C}$ (see Table I).

The measured phase-to-ground voltage and frequency for battery charging is complying with [6]. The voltage unbalance $u_{\mathrm{u}}$, which amounts to $2,73 \%$ for no-charging operation, would be critical for a public network and not acceptable according to [6]. During battery charging, $u_{\mathrm{u}}$ increases to a maximum of $3,79 \%$ and to $3,51 \%$ for the single-phase and the three-phase charging.

The maximum increase of THD factor up to 3,62\% $(+0,71 \%)$ is negligible when a single vehicle is charged. In addition, the voltage of single harmonics within internal network is obviously below their maximum permitted values described in [6]. Fig. 2 shows the voltage difference $\Delta U_{\mathrm{h}}$ at the terminal of the charging
Table I. Measurement results in the laboratory.

\begin{tabular}{lccc}
\hline Charging vehicle & Vehicle A & Vehicle B & Vehicle C \\
\hline Voltage drop & $-9,0 \mathrm{~V}$ & $-7,0 \mathrm{~V}$ & $-7,9 \mathrm{~V}$ \\
& $(-3,8 \%)$ & $(-3,0 \%)$ & $(-3,4 \%)$ \\
Charging current & $16,0 \mathrm{~A}$ & $13,3 \mathrm{~A}$ & $14,3 \mathrm{~A}$ \\
Charging system & $3-$ phase & 1 -phase & 1 -phase \\
THD & $3,27 \%$ & $3,33 \%$ & $3,62 \%$ \\
& $(+0,35 \%)$ & $(+0,42 \%)$ & $(+0,71 \%)$ \\
$u_{\mathrm{u}}$ & $3,51 \%$ & $3,42 \%$ & $3,79 \%$ \\
& $(+0,78 \%)$ & $(+0,69 \%)$ & $(+1,06 \%)$ \\
\hline
\end{tabular}

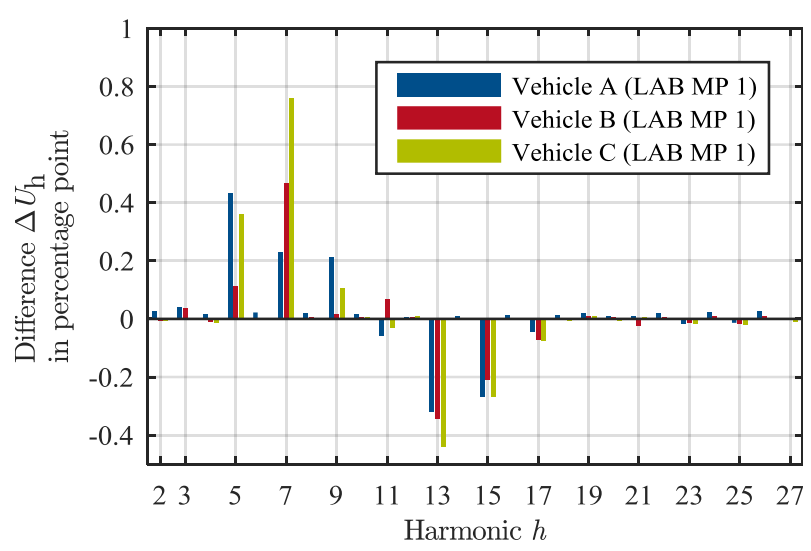

Fig. 2. Difference of harmonic voltages $\Delta U_{\mathrm{h}}$ by charging of three vehicles in the laboratory.

station (corresponds to MP 1 in Fig. 1) for the three different vehicles. The difference $\Delta U_{\mathrm{h}}$ in percentage point between the value during charging in $\%$ and the base value in $\%$ is calculated according to eqn. (3). This comparison method provides information about the impact of the battery charging on local power quality. The measuring inaccuracy is owed to the dynamic situation in the distribution network such as the power supply from the PV system.

$$
\Delta u_{\mathrm{h}}=u_{\mathrm{h}, \%}^{\text {charging }}-u_{\mathrm{h}, \%}^{\text {no-charging }}
$$

An increase of the 5th and 7th harmonic of up to $+0,43$ and $+0,76$ percentage point respectively as well as a decrease of the 13th and 15th harmonic of up to $-0,44$ and $-0,27$ percentage point can be observed for investigated vehicles. It can also be seen that a filter with a tuning frequency of about $600 \mathrm{~Hz}$ is installed within the charging devices of all electric vehicles. The changes of the harmonic from 28th to 50th are lower than $0,05 \%$ and therefore negligible for the considerations.

\section{B. Measurements in a smart home}

On the campus of the Technische Universität Darmstadt the access to a smart home (surPLUShome) and to the substation is provided. The power quality inside the smart home and in the public network is investigated without and with battery charging. The overview of the study cases of power quality analysis is listed in Table II for the measurements in the laboratory and in the surPLUShome. 


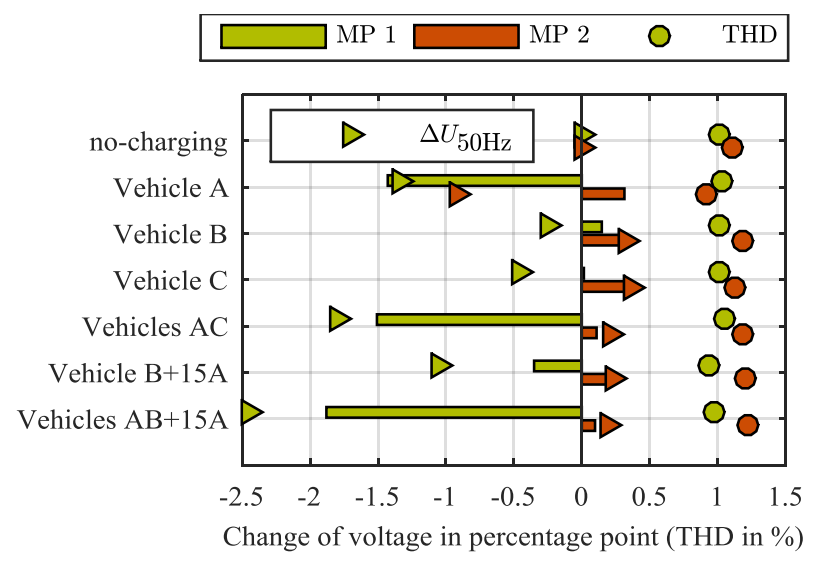

Fig. 3. Change of RMS voltage at two measurement points.

Table II. Study cases of power quality analysis.

\begin{tabular}{|c|c|c|c|c|}
\hline \multirow{2}{*}{ Name } & \multicolumn{3}{|c|}{ Charging of Vehicle: } & \multirow{2}{*}{$\begin{array}{c}\text { Add. load } \\
\text { in phase } \mathrm{L}_{1} \\
\text { "+15 A" }\end{array}$} \\
\hline & A & B & $\mathrm{C}$ & \\
\hline Vehicle A & $\begin{array}{c}\text { LAB+ } \\
\text { MP } 1 / 2\end{array}$ & & & \\
\hline Vehicle B & & $\begin{array}{l}\mathrm{LAB}+ \\
\mathrm{MP} 1 / 2\end{array}$ & & \\
\hline Vehicle C & & & $\begin{array}{c}\mathrm{LAB}+ \\
\mathrm{MP} 1 / 2\end{array}$ & \\
\hline Vehicles AC & MP $1 / 2$ & & MP $1 / 2$ & \\
\hline Vehicle $B+15 A$ & & MP $1 / 2$ & & MP $1 / 2$ \\
\hline Vehicles $A B+15 A$ & MP $1 / 2$ & MP $1 / 2$ & & MP $1 / 2$ \\
\hline
\end{tabular}

Fig. 1 shows the single-line diagram of the investigated network with two measurement points for voltage and current in each phase. While the first measurement point is allocated directly at the charging station (corresponds to the laboratory setup), the second point is located at the LV side of the distribution transformer.

The measurement is executed with the network analyser DEWE-571. The analysis provides information for distribution network operators about expected changes in LV networks and in home networks. Furthermore, manufacturers of charging stations and electric vehicles should be aware of the influences on power quality. The power quality is evaluated again separately for the three electrical vehicles (vehicle A, B and C) as well as for the parallel charging of two vehicles (vehicles $\mathrm{AC}$ and $\mathrm{AB}$ ) and for a case of an additional one-phase load in phase $L_{1}$ of $15 \mathrm{~A}$ into the home network (cases with "+15 A").

Fig. 3 shows an additional voltage drop caused by the battery charging in the investigated cases. The horizontal bars correspond to the RMS voltage and the triangles to the RMS voltage with the fundamental frequency of $50 \mathrm{~Hz}$. Based on the no-charging values the voltage drops are calculated according to eqn. (4).

$$
\Delta u_{\mathrm{RMS}}=\frac{\left(u_{\mathrm{RMS}}^{\text {charging }}-u_{\mathrm{RMS}}^{\text {no-charging }}\right)}{u_{\mathrm{RMS}}^{\text {no- charging }}}
$$

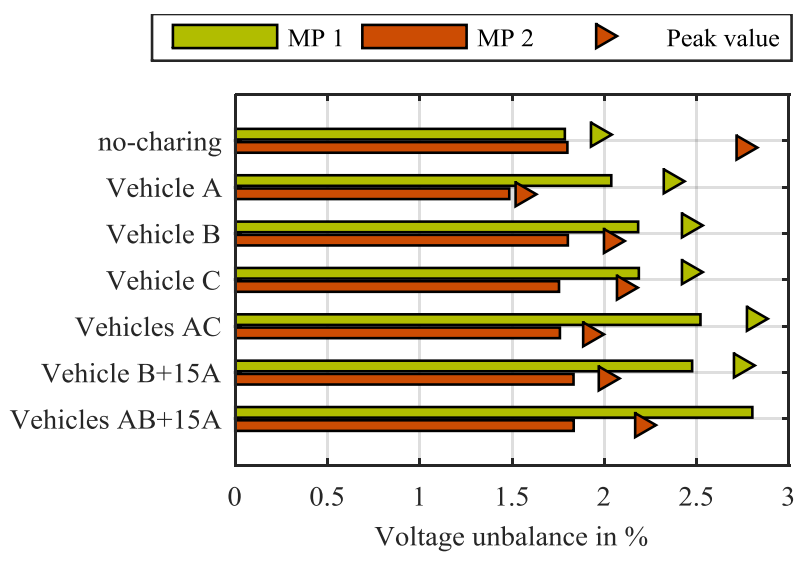

Fig. 4. Voltage unbalance in the investigated network.

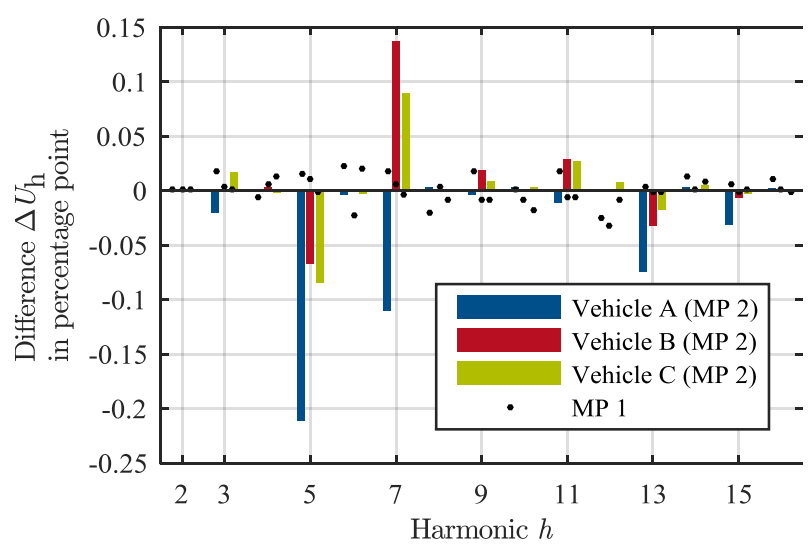

Fig. 5. Voltage difference $\Delta U_{\mathrm{h}}$ of harmonics.

The three-phase charging (case with Vehicle A) causes a voltage drop at the terminal of the charging station less than $1,5 \%$. The voltage drop for the investigated worst case with the simultaneous charging of two batteries and an additional load is not higher than $2 \%$. The measurements at the LV side of the transformer show voltage changes, which is smaller than $0,5 \%$ and can be neglected. The reference value (no-charging measurement) does not consider the fluctuation of network voltage in time or position of the transformer's tap changer. A slight drop of the voltage on the internal network impedance indicates a strong distribution network. The battery charging has an higher impact on the fundamental voltage of $50 \mathrm{~Hz}$ than on the RMS voltage and the voltage drop achieves in the worst-case $2,5 \%$. In contrast to these results the measurement in the laboratory proves a weak network with a higher voltage drop and higher values of the harmonics at charging. The THD factor at the charging station and at the transformer remains consistent and amounts about respectively $1 \%$ and $1,2 \%$. No significant tendency is observed. In case Vehicle A the decrease of the THD factor can be explained by significant differences between reference values and current network conditions.

A change of the voltage unbalance for the considered measurements is listed in Figure 4 and is calculated as 10 min. mean value. With an increase of the unbalanced load (unbalanced charging and connection of the one- 
phase load) the unbalance voltage increases slightly at the network connection to $1,8 \%$ and stays under the permitted value of $2 \%$ [6]. The calculated peak values amount about $2 \%$ and have a maximum of $2,2 \%$. At the three-phase charging (Vehicle A) a lower voltage unbalance is achieved. On the one hand, it is caused by a dynamic situation in the network e.g. time-dependent supply from PV installation. On the other hand, some internal filters installed in a rectifier can decrease this harmonics, which are responsible for the negative sequence of the voltage (see chapter 2.C). The aboveaverage decrease of the voltage of the 5 th harmonic can be seen in Fig. 5. At three-phase charging the voltage difference $\Delta U_{5}$ amounts in- 0,21 percentage point.

In the LV private network, e.g. the households, the limits of voltage characteristics are not regulated by law. Therefore, in this investigation the assumption is given that the power quality standard EN 50160 (valid for a public network such as the connection point of the household to the grid) is valid in an overall network of the household too. At the measurement point at the charging station the voltage unbalance increases from $1,8 \%$ for no-charging conditions to $2,8 \%$ in the worstcase. Following the voltage unbalance violates the power quality limit of $2 \%$ by the operations with any electrical vehicle. However the impact of a voltage unbalance over $2 \%$ on the household appliances should be investigated in the future.

\section{Evaluation of harmonic voltages}

The overview of the maximum harmonic voltages up to $h=50$ are presented in Fig. 6 considering all investigated cases. The bars represent the results at the public grid and the points the corresponding voltages at the charging station. All harmonic voltages are below the limit and fulfil the standard [6] for power quality in public grids. The comparison shows the positive effect of a damping of higher harmonics $h \geq 19$ via feeder cable at the transformer, e.g. the harmonic $h=29$ is about $0,06 \%$ smaller. The significant impact on the fundamental voltage characteristic has the 5 th and 7 th harmonic of the voltage. Those harmonic voltages are single cases in which the harmonic voltage is higher at the transformer than at the charging station. Due to the dominant value of those harmonic voltages the outcome of the higher THD factor of $1,23 \%$ at the public grid can be explained. Additionally, the damping of both harmonic voltages in the household can be calculated.

According to [9] the following harmonic voltages correspond with the negative sequence of the voltage:

$$
h_{\text {neg. sequerce }}=2+3 n \Leftrightarrow n \in \mathrm{Z}^{+}
$$

When comparing eqn. (5) and the harmonic voltages, the following harmonics $h=5,11,17,23,29$ have a significant impact on the accruement of the negative sequence of the voltage.

Fig. 7 shows the voltage difference $\Delta U_{\mathrm{h}}$ at one-phase charging and at an increase of load (additional load at smart home and three-phase charging). Due to charging the electric vehicle, the power quality in the public network decreases. In case of a higher load the 7th and 11 th harmonic of the voltage slightly increases. Furthermore the negative voltage change is observed for the 5th and 13th harmonic. When comparing these results with the laboratory measurement the similar behaviour can be interpreted as an influence of any filter $600 \mathrm{~Hz}$. Due to better power quality in the public grid than in the laboratory (smaller values of THD and $u_{\mathrm{u}}$, see Fig. 5), the investigated changes of the voltage are lower in the smart home. The reactance $X_{\text {cable }}$ of a cable depends proportionately on the inductance $L$ and frequency $f$. Consequently, the reactance of the feeder cable achieves the higher values for higher frequencies at the constant inductance. The positive effect of damping of higher harmonic $h \geq 15$ by the feeder cable can be observed at the LV side of the transformer. Finally, the 5th and 7th harmonic matters in the calculation of the THD with the result that the THD factor at the transformer remains higher than 0,25 percentage point. A comparison with other cases leads to the same conclusion.

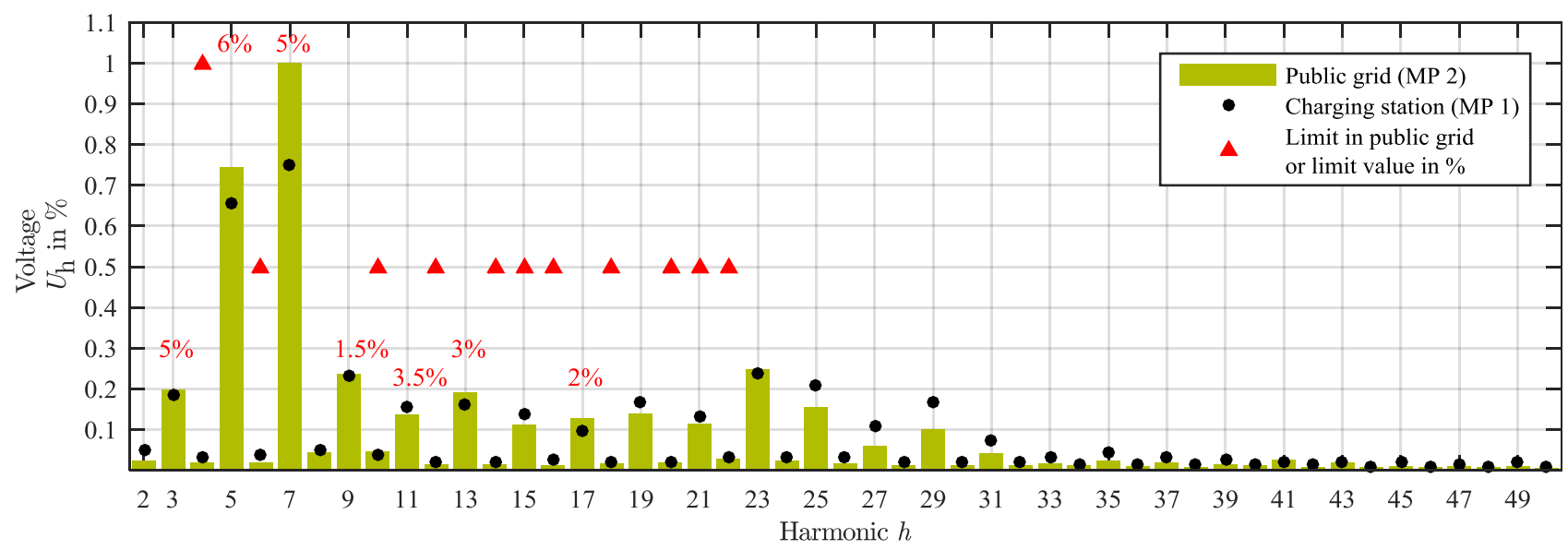

Fig. 6. Maximum harmonic voltages at the LV transformer. 


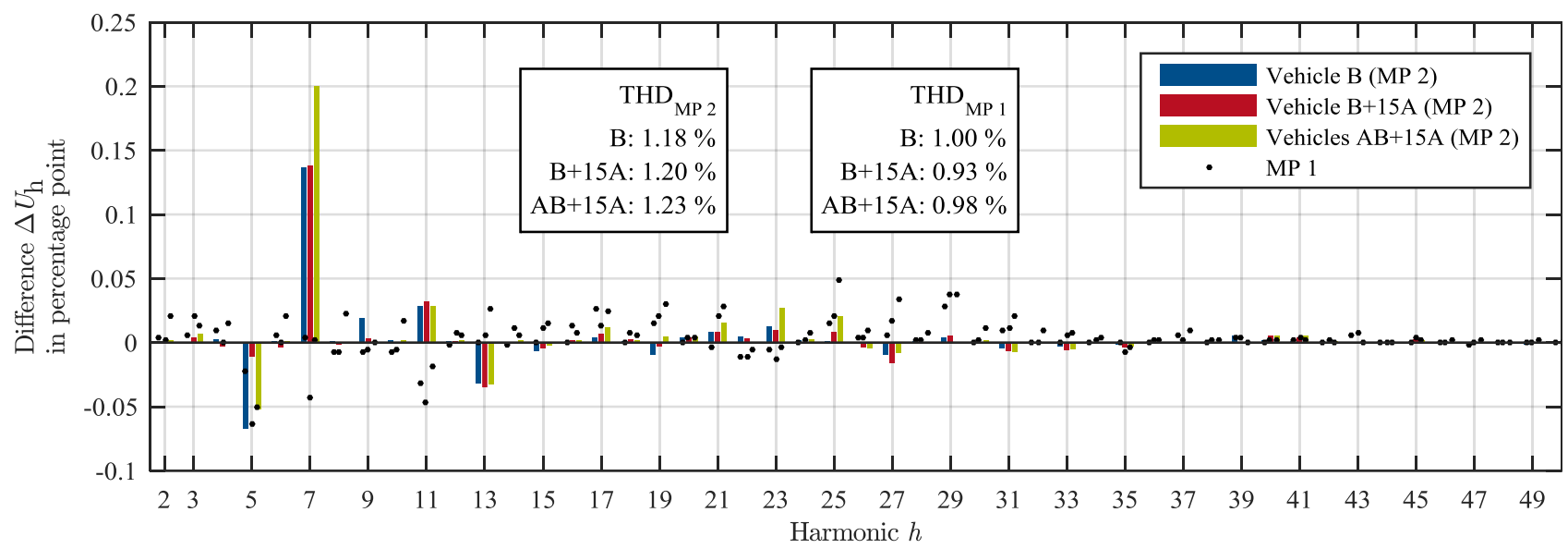

Fig. 7. Harmonic voltages at the public grid by one-phase charging and an increase of load.

Table III. Increase of voltage unbalance by battery charging.

\begin{tabular}{|c|c|c|c|c|c|}
\hline & $\begin{array}{l}\text { Smart } \\
\text { home } \\
\text { in } \%\end{array}$ & $\begin{array}{c}I_{\mathrm{L} 1} \\
\text { in A }\end{array}$ & $\begin{array}{c}\text { Public } \\
\text { network } \\
\text { in } \%\end{array}$ & $\begin{array}{c}I_{\mathrm{L} 1} \\
\text { in A }\end{array}$ & $\begin{array}{l}t_{\mathrm{uu}<2 \%} \\
\text { in } \%\end{array}$ \\
\hline$u_{\mathrm{u}, \text { no-charging }}$ & 1,786 & 0,19 & 1,707 & 4,3 & 75,3 \\
\hline$\Delta u_{\mathrm{u}, \text { VehicleA }}$ & 0,252 & 16,0 & $-0,222$ & 17,5 & 100,0 \\
\hline$\Delta u_{\mathrm{u}, \text { VehicleB }}$ & 0,397 & 13,3 & 0,095 & 13,7 & 99,9 \\
\hline$\Delta u_{\mathrm{u}, \text { VehicleC }}$ & 0,401 & 14,3 & 0,047 & 14,9 & 99,6 \\
\hline$\Delta u_{\mathrm{u}, \mathrm{AC}}$ & 0,735 & 30,6 & 0,052 & 24,7 & 100,0 \\
\hline$\Delta u_{\mathrm{u}, \mathrm{B}+15 \mathrm{~A}}$ & 0,690 & 13,0 & 0,126 & 29,4 & 99,9 \\
\hline$\Delta u_{\mathrm{u}, \mathrm{AB}+15 \mathrm{~A}}$ & 1,016 & 29,2 & 0,127 & 45,0 & 99,8 \\
\hline $\begin{array}{l}2 \cdot \Delta u_{\mathrm{u}, \mathrm{B}+15 \mathrm{~A}} \\
\text { (assumption) }\end{array}$ & - & - & 0,252 & 60 & - \\
\hline
\end{tabular}

\section{Determination of maximal number of charging vehicles}

The harmonic voltages and THD factors stay below the permitted limits in each investigated case. The future problem in the public network can be coupled with the voltage unbalance and a violation of the limit of $2 \%$. In the Figures 6 and 7 the significant impact of charging on the 5th and 7th harmonic is observed. If the harmonic voltages are explained by using the symmetrical component, it can be assumed that the 5th, 11th, 17th and so on correspond with the negative system of the voltage [9]. For all measured cases the change of the same harmonic is observed (the same behaviour of the rectifier and the similar impact on the system). In assumption that the voltage source of each harmonic remains linear [3], a generally formula can be phrased:

$$
\Delta u_{\mathrm{u}}=u_{\mathrm{u}, \text { no-charging }}+\sum_{n=1}^{\infty} \Delta u_{\mathrm{u}, \text { charging } n}
$$

The comparison of the results in Table III shows that the three-phase charging doesn't have a relevant impact on the voltage unbalance in the public grid (case $\mathrm{B}+15 \mathrm{~A}$ with $\mathrm{AB}+15 \mathrm{~A}$ and $\mathrm{A}$ with $\mathrm{AC}$ ). The equal increase of a load in each phase does not induce an additional negative system of the voltage (by neglecting any additional harmonic voltages from a rectifier). Regarding the linear assumption of the result by one-phase charging, maximum four electric vehicles can be charged at the same time so that the power quality limits would not be violated. In the investigated cases all one-phase rectifier are supplied from the same phase L1. This case corresponds with an additional one-phase load of $60 \mathrm{~A}$. In the smart home installation the impact of battery charging occurs with a maximum of $+0,4 \%$ for charging a single vehicle and in the investigated case with a maximal load of $+1,0 \%$. The increase of the voltage unbalance at the charging station at its minimum is four times higher than in the public grid (vehicle B).

\section{Conclusion}

During battery charging of electric vehicles the voltage drop of the fundamental voltage $U_{50 \mathrm{~Hz}}$ is higher more than the RMS voltage drop. This has direct influence on operation of electrical equipment with detection of fundamental voltage such as e.g. under and over-voltage protection. (see Fig. 3).

Properly measurements of a voltage unbalance at the LV transformer are less critical than at the charging station. During battery charging the voltage unbalance remains below $2 \%$ in over $95 \%$ of the measured time periods (see Table III). In the no-charging mode (operation of LV transformer close to open loop condition, see Fig. 1) voltage unbalance exceeding their limits occurs in over $20 \%$ of time. Due to unbalanced low-load condition this operation can be admitted exceptionally.

Due to the high voltage unbalance of $1,71 \%$ in public grid (MP2) at no-charging mode, the integration of more than four electrical vehicles should be investigated in detail. Therefore it can be severe to adhere to power quality standards of public networks. Designed to improve the power quality in a household, the load should by split equally on each phase. The feeder cable for a charging station should be designed specially. The comparison of laboratory and smart home shows high impact of short-circuit power on voltage drop and damping of harmonic voltages. 
A similar internal structure of one-phase charging cable (designed for a charging by a three-phase charging station) is observed for different types of charging cables. Both charging cables use the same phase L1 to charge the battery. In case of an area with more electric vehicles this point should be considered for optimal load balancing. The manufacturing process can be considered in standards.

During the charging of electric vehicles the limits of harmonic voltages $h \leq 25$ are not violated in all cases. A significant part of higher harmonic voltages (see Fig. 6) is observed. Therefore the newer power quality standard IEC TS 62749:2015 [10] with consideration up to the 50th harmonic voltages overlaps the standard EN 50160 [6] regarding power quality limitation.

\section{References}

[1] Bundesministerium für Verkehr, Bau und Stadtentwicklung, "Elektromobilität - Deutschland als Leitmarkt und Leitanbieter", [Online], Available: http://www.bmvi.de/ SharedDocs/DE/Publikationen/G/elektromobilitaet-deutschl and-als-leitmarkt-und-leitanbieter.pdf, 2011.

[2] M. Khederzadeh, "Power quality assessment in distribution systems embedded with electric vehicle and its enhancement by optimal charging", in CIRED, 23rd International Conference on Electricity Distribution, Lyon, 2015.

[3] B. Grasel, A. E. Neuhold, M. Oberhofer, "Results of harmonic interactions of EV chargers and PV systems", in CIRED, 23rd International Conference on Electricity Distribution, Lyon, 2015.

[4] L. Kutt; E. Saarijarvi, M. Lehtonen, H. Molder, J. Niitsoo, "A review of the harmonic and unbalance effects in electrical distribution networks due to EV charging", in Environment and Electrical Engineering (EEEIC), 12th International Conference on , vol., no., pp.556-561, 2013.

[5] Y. Qin; M. Kezunovic, "Impact analysis of Electric Vehicle charging on distribution system," in North American Power Symposium (NAPS), vol., no., pp.1-6, 2012.

[6] DIN EN 50160, Voltage characteristics of electricity supplied by public distribution networks, 2010.

[7] J. Lepka, W. Xu, G. Simard, "Power Quality Impact of Electric and plug-in Hybrid Vehicles", in CIRED, 23rd International Conference on Electricity Distribution, Lyon, 2015.

[8] M.N. Moschakis, E.L. Karfopoulos, E.I. Zountouridou, S.A. Papathanassiou, "Adapting EV-microgrid concepts to european grid standards related to power quality", in Intelligent System Application to Power Systems (ISAP), 16th International Conference on, vol., no., pp.1-6, 2011.

[9] ANSI/IEEE Std 141-1986, "IEEE Recommended Practice for Electric Power Distribution for Industrial Plants (IEEE Red Book)", vol., no., pp.1-609, 1986.

[10] M. Schwenke, "Requirements to measurement of Power Quality from Energy turn-around", in VDE-Kongress, Frankfurt am Main, 2014. 